MARY BARBER AND O. A. OKUBADEJO: MATERNAL AND NEONATAL LISTERIOSIS

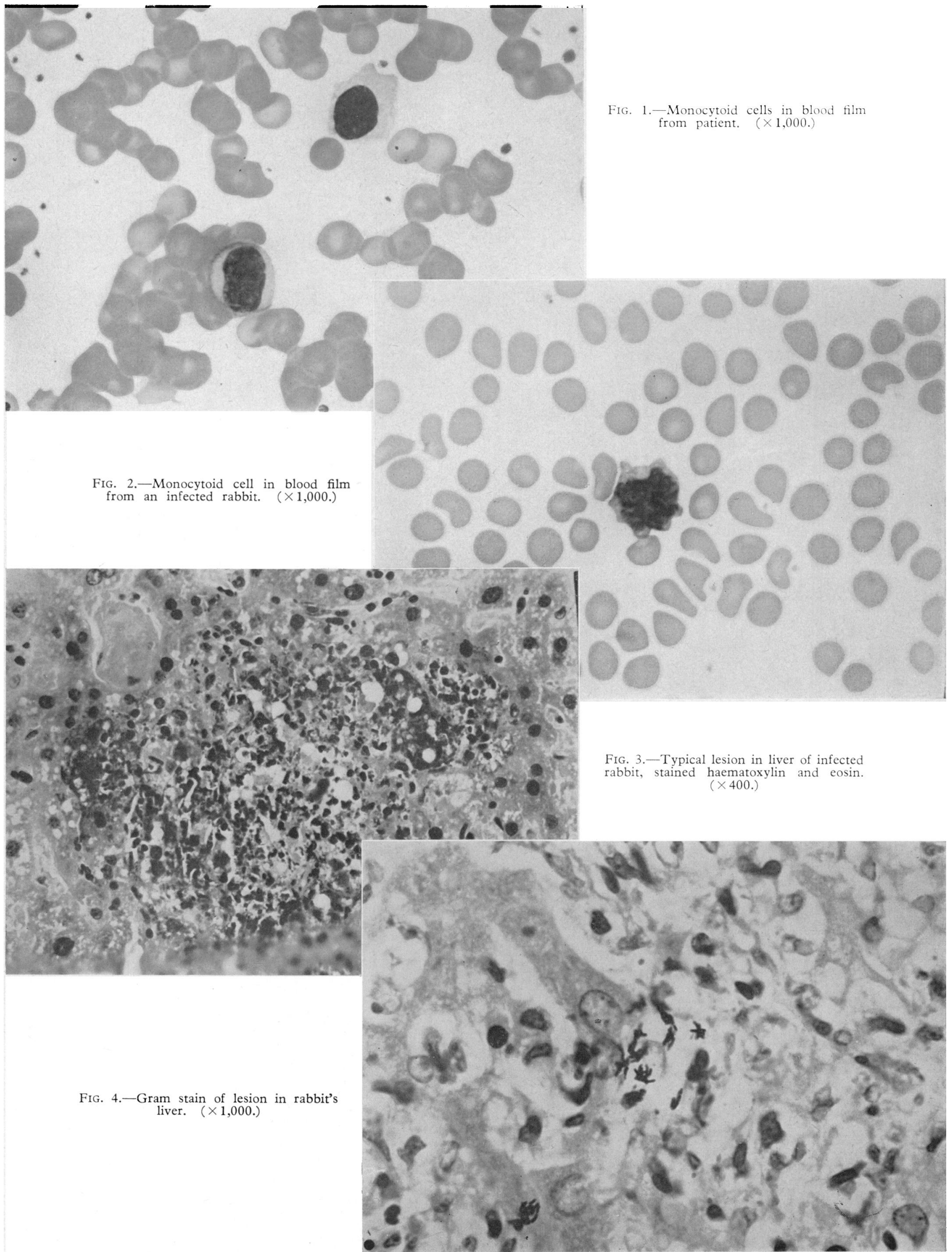




\section{Summary}

Ethacrynic acid is an effective diuretic in doses ranging from 25 to $450 \mathrm{mg}$. daily. It is more potent than either organomercurial or benzothiadiazine diuretics. An excessive diuresis may occur after ethacrynic acid, and a test dose is recommended for patients new to the drug. Benzothiadiazines given with ethacrynic acid formed the most potent combination of diuretics tried.

Urinary potassium losses are greater after ethacrynic acid than after benzothiadiazines. In resistant cases spironolactone (Aldactone-A) given with ethacrynic acid did not prevent high rates of potassium excretion. Potassium chloride supplements are desirable whenever ethacrynic acid is prescribed, alone or in combination with potassium-sparing agents. The incidence of hypochloraemic hypokalaemic alkalosis is discussed.

Agranulocytosis was observed in two patients, but the causal relationship was not established with any certainty.

Ethacrynic acid is best used in the treatment of patients with resistant oedema: in such cases we have found it invaluable.

Part of this work was done when J. G. G. Ledingham was in receipt of a Leverhulme Research Fellowship at the Institute of
Clinical Research, and especial thanks are expressed to Dr. J. D. N. Nabarro for encouragement and advice at that time. We are grateful to Dr. J. J. F. Merry, of Messrs. Merck Sharp and Dohme, for supplies of ethacrynic acid.

\section{REFERENCES}

Beyer, K. H., Baer, J. E., Michaelson, J. K., and Russo, H. F. (1965). 7. Pharmacol., 147, i.

Bourke, E., Counihan, T. B., Keelan, P., and Ryan, M. (1965). J. Irish med. Ass., 56, 1.

Cannon, P. J., Ames, R. P., and Laragh, J. H. (1963). 7. Amer. med. Ass., 185, 854.

Heinemann, H. O., Stason, W. B., and Laragh, J. H. (1965). Circulation, 31, 5 .

Daley, D., and Evans, B. (1963). Brit. med. F., 2, 1169.

Dollery, C. T., Parry, E. H. O., and Young, D. S. (1964). Lancet, 1, 947. Earley, L. E., and Friedler, R. M. (1964). ๆ. clin. Invest., 43, 1495.

Foltz, E. L. (1963). Fed. Proc., 22, 598.

Goldberg, M., McCurdy, D. K., Foltz, E. L., and Bluemle, L. W. (1964) f. clin. Invest., 43, 201.

Ledingham, J. G. G., and Bayliss, R. I. S. (1965). Clin. Pharmacol. Ther., 6, 474.

Maher, J., F., and Schreiner, G. E. (1965). Ann intern. Med., 62, 15.

Melvin, K. E. W., Farrelly, R. O., and North, J. D. K. (1963). Brit. med. f., 1,1521

Müller, P., and Schaub, F. (1964). Klin. W schr., 42, 958.

Stock, R.' J., Mudge, G. H., and Nurnberg, M. J. (1951). Circulation, 4, 54 .

\title{
Maternal and Neonatal Listeriosis: Report of Case and Brief Review of Literature of Listeriosis in Man
}

\author{
MARY BARBER,* M.D., F.C.PATH. ; O. A. OKUBADEJO, $†$ M.B., B.S., D.C.P.
}

[Wirh Special Plate]

Brit. med. F., 1965, 2, 735-738

Listeria monocytogenes, 40 years after its first isolation and description by Murray, Webb, and Swann (1926), remains, at least for the epidemiologist, a baffling microbe (see Gray, 1963). Animals, birds, and humans are all susceptible to infection, but in view of its widespread distribution in nature such infections are relatively rare and the mode and source of infection are in nearly all cases obscure.

In humans, infection usually takes the form of meningitis, " infectious mononucleosis," or a septicaemic condition of the foetus or newborn infant usually referred to as granulomatosis infantiseptica. In some parts of the world, notably Germany (Potel, 1958) and the United States (Seeliger and Cherry, 1957), the latter appears to be the most frequent form of infection and several recent reports suggest that genital infection with Listeria monocytogenes may be a cause of repeated abortion (Rappaport et al., 1960 ; Gray, 1960 ; Dungal, 1961 ; Toaff et al., 1962).

In Britain, until recently, the disease not only appeared to be more rare than in many other places but of the 11 cases reported in medical journals all but one (Webb, 1943) were meningeal infections (see Beck, 1961). Since 1961 three further cases, all meningitis, have been reported in medical journals (McKinnon and Swithinbank, 1961 ; Harding and Brunton, 1962), bringing the total to 14 . In addition the weekly report of the Public Health Laboratory Service has recorded an increasing number of cases of listeriosis since 1961, and in the first six months

* Professor Barber, who died on 12 September 1965, was Professor of Clinical Bacteriology at the Postgraduate Medical School of London. An obituary notice was printed in the B.M.F. of 18 September (p. 707). t Registrar, Department of Bacteriology, Postgraduate Medical School of
London. of 1965 the number is already eight, but again all the infections have been meningeal. Although five of the 13 fully reported meningeal infections were neonatal (Edmunds et al., 1957 ; Barrow and Pugh, 1958 ; Moore and Whitmore, 1960 ; Harding and Brunton, 1962), in only one was there any suggestive evidence that infection was from the mother (Barrow and Pugh, (1958), and this was unproved. The case reported here represents, therefore, the first bacteriologically confirmed infection in both mother and infant recorded in Britain, although even in this case the patient was not British. Moreover, although Listeria monocytogenes has been isolated from the vagina in patients with a history of abortion (Rappaport et al., 1960) the authors do not know of another case where the organism has been isolated from a septicaemic infection in a pregnant woman and subsequently in the newborn infant.

\section{Case Repont}

\section{History and Clinical Findings}

The patient, a Ghanaian woman aged 21, who had arrived in England three weeks previously, was admitted to this hospital on 21 April 1965. She was 28 weeks pregnant and gave a history of cough associated with scanty blood-stained sputum and upper abdominal pain for eight days, and fever for two days. She had had malaria four years previously and had been taking suppressive therapy until three weeks before admission. She had had a normal pregnancy and delivery in 1960 and the child was alive and well.

On admission the temperature was $102^{\circ} \mathrm{F}$. $\left(38.9^{\circ} \mathrm{C}\right.$.) and bloodpressure $120 / 80 \mathrm{~mm}$. Hg. No signs of abnormality were detected in the chest, cardiovascular system, abdomen, or central nervous 
system, and there was no evidence of glandular enlargement. The pregnancy was perfectly normal for the period of gestation.

\section{Investigations}

Haemoglobin was $55 \%$ and white cell count 13,499, with polymorphonuclear cells $69 \%$, metamyelocytes $7 \%$, lymphocytes $5 \%$, monocytes $4 \%$, and atypical monocytoid cells $15 \%$. No malarial parasites were seen in the blood. The results of liver-function tests were bilirubin $2 \mathrm{mg} . / 100 \mathrm{ml}$. ; cholesterol $19 \mathrm{mg} . / 100 \mathrm{ml}$.; alkaline phosphatase 8 units; zinc sulphate 6 units. Radiographs of the chest showed slight cardiac enlargement but lung fields were clear. Examination of faeces showed cysts of Anklyostoma duodenale. Blood culture, taken on the day of admission, two days later yielded a small bacillus, thought at first to be Gram-negative bat subsequently identified as Listeria monocytogenes (see below).

\section{Progress}

The patient remained febrile for the next two days, and following the report of the blood culture was put on ampicillin $250 \mathrm{mg}$. sixhourly and sent to the Western Fever Hospital. On the night of admission to the latter hospital (24 April) she went into premature labour and gave birth to a $2 \frac{1}{2} \mathrm{lb}$. $(1,180 \mathrm{~g}$.) live infant, which died within a few hours. Listeria monocytogenes was isolated from the cerebrospinal fluid at necropsy.

A few hours after delivery the patient became shocked with an unreadable blood-pressure, although the delivery had not been complicated by post-partum haemorrhage. She was treated with hydrocortisone and pressor amines, and streptomycin was given in addition to ampicillin. She had improved slightly by the next day, but developed an increasing cough with scanty blood-stained sputum from which Staph. pyogenes was isolated. Widespread rales were now heard over the chest, and a radiograph of the chest showed widespread shadowing in both lung fields. In view of the staphylococcus, which was resistant to benzylpenicillin, cloxacillin $500 \mathrm{mg}$. six-hourly intramuscularly was added to the other antibiotics.

Two days later the patient was much better and a radiograph of the chest showed that the lung shadows had almost completely disappeared, but there was increasing cardiomegaly. By 4 May the patient appeared to have almost recovered and all antibiotics were stopped. A chest radiograph, however, showed that the heart was still enlarged and she was transferred back to this hospital. Examination of the heart revealed a thrusting apex beat with widely spaced first and second sounds and a soft apical systolic murmur, but there were no other abnormal physical signs. Radiographs of the chest showed that the heart, although still moderately enlarged, was decreasing in size and the lungs were clear. An electrocardiogram showed non-specific $\mathrm{T}$-wave changes. It was concluded that pulmonary oedema and cardiomegaly due to septicaemia was the most likely diagnosis of the chest condition. The haemoglobin was now $75 \%$ (the anaemia was thought to have been due to infestation with hookworm, for which she had been treated with bephenium hydroxynaphthoate) and the white cell count was 7,000 with $5 \%$ eosinophils, but no abnormal mononuclear cells. The patient left the hospital in good health three weeks after her first admission.

\section{Bacteriology and Serology}

The organism isolated from the blood-stream of the mother and that isolated from the cerebrospinal fluid of the baby appeared to be identical and the following description applies to both.

Morphology and Staining.-Short bacilli of medium width showing no characteristic arrangement; Gram-positive but fairly easily decolourized. When grown at $22^{\circ} \mathrm{C}$. they showed the "tumbling" motility characteristic of Listeria.

Cultural Characteristics.-On blood-agar plates incubated aerobically at $37^{\circ} \mathrm{C}$. the organism gave rise to smooth semitransparent colonies with an entire edge, which were very tiny after 24 hours but reached a size of 1-2 mm. in 48 hours. Similar but slightly smaller colonies were seen on unenriched nutrient agar. There was slight haemolysis on blood-agar plates and the test for soluble haemolysin was positive.

Biochemical Activities.-The organism produced catalase and attacked the following carbohydrates by fermentation (not oxidation, see Hugh and Leifson, 1953) with the production of acid but no gas: glucose, maltose, salicin, rhamnose, dextrin, glycerol, sucrose (after six days), sorbitol (weakly), and cellobiose. It was methyl-red positive, Voges-Proskauer positive, and urease and citrate negative. Tests for decarboxylases were negative.

Pathogenicity.-The organism was shown to be pathogenic for mice and rabbits and gave rise to the characteristic areas of necrosis in the liver of both species (Special Plate, Figs. 3 and 4). Blood counts in an infected rabbit revealed the mononuclear response characteristic of listeriosis; on the fifth day of infection the white cell count was 16,000 , and $40 \%$ of the total were large mononuclear cells. Special Plate, Figs. 1 and 2, show examples of the monocytoid cells seen in blood films from the patient and an infected rabbit.

Antibiotic Sensitivity.-In ditch-plate tests, in comparison with the Oxford staphylococcus, the organism was found to be fully sensitive to ampicillin, streptomycin, and tetracycline and partially sensitive to benzylpenicillin.

Serology.-Samples of serum were collected from the patient on 25 April (four days after admission) and again on 11 May, and examined for agglutinins to the organism isolated from her blood and a stock culture of List. monocytogenes. Against both cultures the titre of the first sample was only 1 in 10, but with the second it had gone up to 1 in 640 .

\section{Necropsy of Infant}

The baby was a female coloured infant of normal development for 28 weeks' maturity. The weight was $1,060 \mathrm{~g}$., length 15 in. $(38.1 \mathrm{~cm}$.$) , shoulder width 5 \frac{1}{2}$ in. $(13.9 \mathrm{~cm}$.), and head circumference $10 \frac{1}{4}$ in. $(26 \mathrm{~cm}$.). The only abnormal finding was patchy atelectasis of both lungs. The heart and pericardium were normal with a patent foramen ovale and a patent ductus arteriosus. No abnormalities were detected in brain and meninges. Histological sections of all organs, except the lungs, were normal.

The placenta weighed $345 \mathrm{~g}$. and showed moderate degenerative changes. Histological sections showed areas of acute inflammation with central necrosis, and many of these areas contained Grampositive cocci and coccobacilli.

Listeria monocytogenes was isolated from the cerebrospinal fluid, but cultures from the placenta yielded Str. faecalis only.

\section{Review of Literature}

\section{Increasing Incidence or Awareness of Listeriosis in Man}

Listeria monocytogenes was first discovered in 1926 by Murray, Webb, and Swann, who proved convincingly that it was the cause of a spontaneous epidemic disease of rabbits in the breeding stock of the Cambridge Field Laboratories. A year later Pirie (1927) isolated a similar organism from gerbilles found dead during plague-survey work in South Africa. Pirie found that cats, dogs, and monkeys were resistant to infection and concluded that it was a pathogen only for small rodents. $\mathrm{He}$ even started to use it in field trials for the extermination of gerbilles.

The first proved human infections to be recorded were four cases of meningitis, three infants and one adult, described by Burn between 1933 and 1936 in Connecticut (see Burn 1933-4, 1935, 1936). In the meanwhile Schultz et al. (1933-4) in California reported the case of a nurse with meningitis due to a new Gram-positive bacillus, and Gibson (1935) in Scotland isolated from another case of meningitis a "diphtheroid" which he noted resembled the bacillus described by Schultz et al. (1933-4). Cultures of these two bacteria, together with one of the original strains of Murray, Webb, and Swann (1926) and one from Pirie (1927), were examined and compared by Webb and Barber (1937) who " failed to find any material difference" between the four strains, in spite of their diverse origin, and concluded that further cases of listeriosis in man were likely to be reported from widely separated districts.

This prediction has now been fulfilled, but after some delay. Seeliger and Cherry (1957) have pointed out that up to 1939, 
29 human cases of listeriosis had been reported, between 1940 and 1949 there were a further 40, but between 1950 and 1955 there were more than 221 . As already indicated in the introduction, the incidence in Britain has been increasing rapidly since 1961. Seeliger and Cherry (1957) conclude that the increasing incidence is mainly due to an increasing awareness of the condition by pathologists. The organism is both difficult to identify and difficult to isolate. With regard to the former it may be dismissed as a contaminating "diphtheroid," or thought to be a streptococcus, or-because of the ease with which it is decolourized-a Gram-negative bacillus. With regard to isolation, although in subculture Listeria grows moderately readily on the usual laboratory media, it is often very difficult to isolate in primary culture, particularly from tissues, even when it is seen to be present in them in large numbers. These authors, and Gray (1960), who supports their contention, recommend primary refrigeration before culture. It has even been suggested that the material to be cultured should be refrigerated and then cultured every few days for two months before discarding it as negative (see Ray and Wedgwood, 1964).

\section{Clinical Manifestations}

The commonest form of listeriosis in man is meningitis or meningo-encephalitis. Alternatively, the disease may be a generalized bacteraemic infection. In adults this is often associated with a circulatory monocytosis and sometimes with glandular enlargement, so that the condition may resemble glandular fever with a negative Paul-Bunnell test. This condition was first described by Nyfeldt (1937) in Scandinavia, who concluded that glandular fever was due to Listeria. Only one such case has been reported in Britain (Webb, 1943).

The newborn and infants in the first year of life are particularly prone to infection, and in the newborn infection is more frequently generalized. Potel (1950-1) in East Germany first described the condition which he named granulomatosis infantiseptica, in which severe generalized infection occurred in the aborted or newborn infants of apparently healthy mothers. He thought the infecting microbe was a Corynebacterium, but it was subsequently shown to be Listeria monocytogenes (see Seeliger and Cherry, 1957). Similar cases were soon described elsewhere, and in 1964 Ray and Wedgwood reported six such cases together with a review of 63 others reported in the United States and Canada. From a wider literature Seeliger and Cherry in 1957 recorded more than 200. Although in the newborn infant the condition was almost invariably fatal, the mothers were either without symptoms or had a mild febrile illness, usually just before or at the time of delivery.

Even in infants Listeria monocytogenes appears to have a predilection for the meninges. As already indicated, all the five neonatal infections so far reported in Britain were meningeal, and in the case reported here the organisms were isolated only from the cerebrospinal fluid. Again in the six cases reported by Ray and Wedgwood (1964) cultures were taken from blood and cerebrospinal fluid, and in three Listeria was isolated only from the cerebrospinal fluid, in a further two from cerebrospinal fluid and blood, and in only one from blood alone.

\section{Epidemiology}

The distribution of listeriosis is extremely widespread. According to Gray (1963) it occurs on all continents except Antarctica, in climates at varied as those of the Arctic circle, South Africa, and the Argentine. Gray (1963) also states that the microbe has been isolated from 35 different species of mammal, 17 fowl, and also from ticks, pond-reared trout, crustaceans, stream-water, mud, sewage, and silage. Moreover, Listeria may survive for many weeks in straw, wood shavings, and food pellets (Gray, 1951), is highly resistant to salting and -for a non-sporing bacterium-to heat, and will grow at $2^{\circ} \mathrm{C}$. (Murray, 1955).

Nevertheless the disease, although much more frequent than was once thought to be the case, is relatively rare, even allowing for the fact that it is often overlooked and that, as already indicated, it is not readily isolated in primary culture. - It is now becoming apparent that in many animals, including man, the disease may be latent with no symptoms (Seeliger and Cherry, 1957 ; Gray, 1963). Listeria has been isolated from nose, vagina, or intestinal tract of a large variety of healthy animals, as well as from the liver and spleen of animals dying from other causes. Gray (1963) draws attention to this and also points out that in human adults listeriosis is not infrequently associated with the late stages of neoplastic or other fatal illness.

The source and mode of infection in man is not known. Direct transmission from man to man appears to be rare, but Line and Cherry (1952) report the occurrence of two Listeria infections in infants in the same ward, and the 13 cases reported by Nyfeldt (1937) and subsequently shown to be due to a single rare serotype (Paterson, 1940) suggest direct spread or contact with the same source. More recently Olding and Philipson (1960) record four cases, three neonatal and one adult, due to a single serotype occurring within a few months within an area of three blocks in Uppsala.

Occasionally direct contact with an infected animal is a source of infection, and the patient recorded here was known to keep chickens, a common source of listeriosis in many parts of the world. But except in veterinarians such a history is not very common. Milk and meat have both been incriminated. With regard to the former Schmidt and Nyfeldt (1938), Wramby (1944), and Potel (1958) have all isolated Listeria monocytogenes from non-pasteurized cows' milk, and Potel (1958), in a report of 58 neonatal infections recently occurring in a single area of East Germany, thought that milk was probably the main source. Pork used as food on a collective farm was incriminated by Gudkova et al. (1958) in Moscow. Eggs are another possible source (see Gray, 1963).

Finally, at least in relation to neonatal infection, man himself appears to be an important disseminator. Although Potel (1950-1) assumed that the infection of the infant was via the mother, Johnston et al. (1955) were the first to prove this bacteriologically. They recorded a case in which a woman gave birth at 35 weeks to an infant who died in a few hours with signs of generalized infection. The mother was febrile and Listeria were isolated from the genital tract. At necropsy on the infant the organisms were cultured from the blood and cerebrospinal fluid. They were also seen in Gram films to be present throughout the lungs, which showed evidence of bronchopneumonia and bronchitis, and also in pus on the surface of the stomach mucosa. It was therefore concluded that the baby had become infected by aspirating and swallowing amniotic fluid containing Listeria. Serological evidence of maternal infection in three cases of neonatal listeriosis was recorded by Girard and Gavin (1957).

Recently it has been shown by Rappaport et al. (1960) in Israel that Listeria may be harboured for long periods in the genital tract of otherwise healthy women and that there is a causal relationship between this and repeated abortion. They isolated the organism from the vagina of 25 out of 34 women with a history of repeated abortion. In a further report the same group of workers (Toaff et al., 1962) examined the semen of 60 husbands of women with a history of repeated abortion and isolated Listeria monocytogenes from three; in two of the cases the same serotype was isolated from the wives. The presence of Listeria in the men was associated with dyspermia. In all three women normal pregnancy followed treatment of both partners with benzylpenicillin and demethylchlortetracychine. 
Evidence that maternal infection with Listeria may be a cause of abortion has come from several other sources. Gray et al. (1955) produced abortions in pregnant does by intraocular infection with Listeria. They also showed that pregnancy appears to predispose to infection with Listeria, since after oral challenge of pregnant rabbits the bacteria could be isolated from the vagina, but this was not the case with non-pregnant animals. Further evidence in humans has come from Seeliger (1958), who found that $16 \%$ of the mothers who gave birth to infants infected with Listeria had a history of previous abortions or stillborn infants. Rost et al. (1958) found that many women with a history of abortion had a high circulating antibody titre to Listeria monocytogenes and also that after antibiotic treatment the women gave birth to healthy full-term infants. These findings and those of other investigators are discussed by Gray (1960), who points out that further studies using a satisfactory isolation technique (see McBride and Girard, 1960) might indicate a high incidence of Listeria in the human genital tract. The single negative study in Britain (Macnaughton, 1962) of 78 women with threatened or incomplete abortion is not necessarily conclusive, since the technique of isolation differed in certain respects from that of Rappaport et al. (1960).

\section{Summary}

A bacteriologically proved case of listeriosis in both mother and prematurely born infant is recorded for the first time in Britain.

A review of the literature indicates that in some parts of the world not only is neonatal listeriosis relatively common but genital listeriosis may be a significant cause of repeated abortion.

Since Listeria monocytogenes is both difficult to obtain in primary culture and easily confused with a skin-contaminating diphtheroid, it is suggested that the low incidence of infection in Britain may be at least partly due to failure to recognize the condition.

We are grateful to our clinical colleagues at this hospital and Dr. E. P. Sullivan, of the Western Hospital, for permission to

\title{
Diverticulum of the Female Urethra
}

\author{
J. H. N. FERRIS,* M.A., M.B., M.A.O., M.R.C.O.G.
}

Diverticulum of the female urethra is a comparatively rare condition. Few cases have been described until the last decade. Pinkerton (1956) attributed this fact to a failure to stress its existence in undergraduate systematic lectures and clinical instruction. Few references to cases in England and Ireland exist (Lane, 1957 ; Hennessy, 1958 ; Felming, 1959 ; Frith, 1960), the total in Ireland being only 17 . One feels, however, that the sparsity of case reports may well be explained by a lack of interest to record such cases as well as the failure to diagnose this condition, which, although less common in these islands, is not so rare as is generally believed.

The diagnosis and treatment of three cases by me prompted this brief review of the condition.

* Senior Obstetrical Registrar, Jubilee Maternity Hospital, Belfast. publish the case and for supplying us with clinical details. We are also grateful to Dr. B. L. Murphy, of the Group Laboratory, St. Stephen's Hospital, for sending us a report of the necropsy on the baby.

\section{REFERENCES}

Barrow, G. I., and Pugh, R. J. (1958). 7. Path. Bact., 75, 9.

Beck, A. (1961). 7. clin. Path. 14, 512

- (1935). F. Bact., 30, 573

- (1936). Amer. Y. Path., 12, 341

Dungal, N. (1961). Lancet, $2,513$.

Edmunds, P. N., Nicholson, D. N., and Douglas, D. M. (1957). Brit. med. F., 2, 188 .

Gibson, H." J.' (1935). F. Path. Bact., 41, 239.

Girard, K. F., and Gavin, W. F. (1957). Ibid., 74, 93

Gray, M. L. (1951). F. Amer. vet. med., 118, 242. (1960). Lancet, 2, 315. (1958). Zh. Mikrobiol. (Mosk.), (English translation), 29, 1372.

Harding, J. W., and Brunton, G. B. (1962). Lancet, 2, 484 .

Hugh, R., and Leifson, E. (1953). \%. Bact., 66, 24

Johnston, W. H., Morton, S. A., Wong, M. H., and Roy, T. E. (1955). Canad. med. Ass. 7., 73, 402 .

Line, F. G., and Cherry, W. B. (1952). 7. Amer. med. Ass., 148, 366.

McBride, M. E., and Girard, K. F. (1960). A. Lab. clin. Med., 55, 153.

McKinnon, D., and Swithinbank, J. M. (1961). Lancet, 2, 516.

Macnaughton, M. C. (1962), Ibid., 2, 484.

Moore, S., and Whitmore, D. N. (1960). Brit. med. 7., 2, 1572.

Murray, E. G. D. (1955). Canad. med. Ass. Ұ., 72, 99.

Webb, R. A., and Swann, M. B. R. (1926). \%. Path. Bact., 29, 407.

Nyfeldt, A. (1937). Hygiea (Stockh.), 99, 433.

Olding, L., and Philipson, L. (1960). Acta path. microbiol. scand., 48, 24.

Paterson, J. S. (1940). 尹. Paih. Bact., 51, 427.

Pirie, J. H. H. (1927). Publ. S. Afr. Inst. med. Res., No. 20, iii, 163.

Potel, J. (1950-1). Zbl. Bakt., i56, 490

Potel, (1958). Zbl. Vet.-Med." Beiheft., i, 70.

Rappaport, F., Rabinovitz, M., Toaff, R., and Krochik, N. (1960). Lancet, 1, 1273.

Ray, C. G., and Wedgwood, R. J. (1964). Pediatrics, 34, 378.

Rost, H. F., Paul, H., and Seeliger, H. P. R. (1958). Dtsch. med. W schr., 83, $1893,1934$.

Schmidt, V., and Nyfeldt, A. (1938). Ugeskr. Lag., 100, 336.

Schultz, E. W., Terry, M. C., Brice, A. T. jun., and Gebhardt, L. P. (1933-4). "Proc. Soc. exp. Biol.' (N.Y.), 31, 1021.

Seeliger, H. P. R. (1958). Listeriose. Barth, Leipzig.

and Cherry, W. B. (1957). Report to U.S. Dept. of Health, Education and Welfare.

Toaff, R., Krochik, N., and Rabinovitz, M. (1962). Lancet, 2, 482.

Webb, R. A. (1943). Ibid., 2, 5.

and Barber, M. (1937).' f. Path. Bact., 45, 523.

Wramby, G. O. (1944). Scand. vet. T., 34, 277.
Burn, C. G. (1933-4). Proc. Soc. exp. Biol. (N.Y.), 31, 1095

(1963). Amer. F. publ. Hlth, 53, 554.

Gudkova, E. I., Mironova, K. A., Kus'minskii, A. S., and Geine, G. O. A.

A married woman aged 39 had a six-year history of recurrent cystitis and had had two uncomplicated confinements. She was referred to the gynaecological registrar by a surgical colleague after prolonged and unsuccessful investigation and treatment of her urinary complaint.

She complained of a severe pain in the vagina, intermittent for at least six years. This was more severe one week before and after menstruation. Frequency and urgency of micturition, together with pain in the vagina during micturition, were also frequent symptoms, as was deep dyspareunia. All these symptoms had recurred often despite treatment. Intravenous pyelography in 1959 and 1961, cystoscopy in 1959 and 1961, and urethroscopy in 1961 were all normal. Coliform urinary infection had been treated on four occasions. 